\title{
Cubic Meter per Cubic Meter
}

National Cancer Institute

\section{Source}

National Cancer Institute. Cubic Meter per Cubic Meter. NCI Thesaurus. Code C70456.

A unit of volume fraction expressed as a volume of the constituent in cubic meters per the volume of the system represented in cubic meters. 